Whitworth Digital Commons

Whitworth University

Library Faculty Scholarship

Library

$3-2018$

\title{
Tools and Principles for Effective Online Library Instruction: Andragogy and Undergraduates
}

Kathy Watts

Whitworth University, kwatts@whitworth.edu

Follow this and additional works at: https:// digitalcommons.whitworth.edu/libraryfaculty

Part of the Library and Information Science Commons

\section{Recommended Citation}

Watts, K. A. (2018). Tools and principles for effective online library instruction: Andragogy and undergraduates. Journal of Library \& Information Services in Distance Learning. doi:10.1080/1533290X.2018.1428712.

This Peer Reviewed Article is brought to you for free and open access by the Library at Whitworth University. It has been accepted for inclusion in Library Faculty Scholarship by an authorized administrator of Whitworth University. 
Tools and Principles for Effective Online Library Instruction:

\section{Andragogy and Undergraduates}

\section{Introduction}

Academic libraries have been using the internet to provide instruction for many years. With the aim of improving instruction and user experience, librarians have been studying and evaluating online teaching methods for just as long. As far back as 1999 - truly a long time in internet years - Dewald (1999) cautioned librarians not to use the web for instruction simply because it is there. Rather, as with face-to-face instruction, sound principles of learning theory and instructional design should inform the content, design, and delivery of online instruction. The literature about online library instruction is a rich resource for librarians in search of research and theories to support the design of effective online instruction. It can be difficult, however, to summarize the literature because the research methods, student context, and type of online instruction studied and evaluated vary widely.

The literature selected for this review is focused on asynchronous, online instructional delivery methods and techniques. Some of the literature compares face-to-face instruction with online instruction (Gonzales, 2014), while other research compares different methods of online instruction. Of the latter. some studies focus on specific tutorial software or delivery methods (Artemchik, 2016; Held \& Gil-Trejo, 2016; Mery, DeFrain, Kline, \& Sult, 2014; Mestre, 2012; Mikkelsen \& McMunn-Tetangco, 2014; Stiwinter, 2013; Stonebraker, Robertshaw, \& Moss, 2016; Turner, Fuchs, \& Todman, 2015). Other studies examine best practices and educational principles for online instructional design (Bowles-Terry, Hensley, \& Hinchliffe, 2010; Gonzales, 2014; Halpern \& Tucker, 2015; Hess \& Hristova, 2016; Lange, Canuel, \& Fitzgibbons, 2011; Mestre, 2010; Scales, Nicol, \& Johnson, 2014). Although focused on a wide range of topics, 
these authors agree on one thing: online instruction - whether semester-length, one-shot tutorials, point-of-need instruction, or instruction for flipped classrooms - is becoming a primary means for delivering library instruction. The trend to provide more instruction online will only grow as more colleges experience an increase in online and hybrid courses and shifts in library staffing, both of which necessitate delivering instruction online and asynchronously. Other drivers of online library instruction include the efficacy of point-of-need instruction and the opportunity to provide instruction for students with different learning styles.

\section{Evaluation of instruction delivery tools}

The literature selected for this review can be divided into studies that compare two or more types of tutorial delivery systems, studies that evaluate the efficacy of one type of tutorial, articles that describe how principles of learning theory and learning styles can improve tutorial learning outcomes, and articles that focus on web and instructional design to improve student learning using online tutorials. A term used frequently in the literature, when referring to the design of tutorials, is "interactive." However, in that same literature the definition has various interpretations. For the purposes of this literature review, "interactive" will refer to the ability of a student to do tasks, answer questions, or receive feedback during the course of a tutorial.

Using the above definition, two interactive instructional delivery methods have been examined in the literature: Guide on the Side and Adobe Captivate. Guide on the Side is an opensource software developed by the University of Arizona. It utilizes a pop-up type window that sits either within or just on the outside of a web browser window. The window contains information, instructions, input fields, and feedback as students use the browser window to follow the instruction and complete the tasks. The second software, Adobe Captivate, can also create interactive tutorials, but it integrates screencast videos with quizzes and feedback and uses 
a simulation of a web page. As with Guide on the Side, students receive instruction, complete tasks, and receive feedback as they work through the instruction. The primary difference is that with Guide on the Side students are working with the live web site and with Adobe Captivate they are working with a simulation.

When studied as an interactive method for teaching students how to accomplish library research tasks, Guide on the Side proved to be not only an effective way for librarians to provide asynchronous instruction, but one that students appreciated for its interactivity, clear instructions, and simplicity of use (Artemchik, 2016). Students in Artemchik's study were not required to complete any tutorials, but the majority did use - and complete - them. This group was compared to those who received no instruction, and although some instruction is likely better than no instruction at all, the results indicate that Guide on the Side tutorials successfully provided instruction and retained students' attention. Other studies examining Guide on the Side compared it to screencast videos but used different evaluation methods. Mery et al. (2014) and Stonebraker et al. (2016) used pre- and post-tests to determine how much students learned from each tutorial method, while Mikkelsen and McMunn-Tetangco (2014) surveyed student preference for a tutorial type. Mery et al. (2014) hypothesized that based on active learning theory, students who used Guide on the Side would perform better on post-tests, but their results showed that both methods were equally effective. Stonebraker et al. (2016), on the other hand, found that Guide on the Side had distinct advantage over screencasts: students using Guide on the Side not only performed better on post-tests, but those students whose pre-test skills were lowest demonstrated the greatest improvement on post-tests.

Students who viewed tutorials created with Adobe Captivate also demonstrated improvements on post-tests (Held \& Gil-Trejo, 2016; Stiwinter, 2013), but some reported a 
preference for more interaction on some of the tutorials, believing that interaction would help retain their attention (Held \& Gil-Trejo, 2016). Other evaluative comments by students led Held and Gil-Trejo (2016) to draw a similar conclusion as did Mikkelson and McMunn-Tetangco (2014): that learning styles influence the efficacy of a tutorial style. Stiwinter (2013) used a variety of methods in one tutorial - web simulation, video, static web pages, and Prezi - and found that web simulation methods produced better learning outcomes.

Other studies used similar comparison methods to those mentioned above but compared non-interactive online instruction: screencast videos and static web pages or downloadable documents (Mestre, 2012; Turner et al., 2015). In a screencast video, a librarian demonstrates actions and inputs on a web page or a software program, usually with voice narration that describes the actions as they are being performed. Most of the screencasts discussed in the literature were created with Captivate, Camtasia, or Jing, and all incorporated voice narration. Video instruction offers no opportunity for students to receive feedback or perform tasks within the tutorial, but it does provide a visual demonstration of an actual task or skill or a visualization of a concept. Static web pages consist of text and screenshots of web pages or software programs to demonstrate a skill or explain a concept, usually in a sequential step-by-step format. Both methods, although not interactive, allow librarians to use visual cues to call attention to or highlight important skills or concepts. Interestingly, in both Mestre's (2010) and Turner's (2015) studies, static web pages were more effective formats for delivering instruction for most students. In addition to learning more, students in both studies preferred the static pages for ease of navigation and the ability to review content. In contrast to the studies of interactive tutorials, where the most effective tutorials were those that allowed students to work within a web page simulation, the least active format was most effective here. Students in Mestre's (2010) study of 
learning styles and tutorial types preferred the ability to self-pace, skip to certain content, and recreate the tutorial steps as they proceeded through the tutorial.

\section{Evaluation of instruction delivery techniques}

The selected studies indicate that a large number of variables influence both student preferences for online instruction and student learning outcomes. Since the studies vary widely on what types of tutorials were examined and how students' learning was assessed, few studies offer the opportunity to compare results. Consequently, there are few generalizations that come out of the literature. Indeed, as mentioned by some of the literature, when evaluating different tutorial delivery formats, generalizations are not helpful because librarians want to instruct all students well, not just most. However, the literature is helpful in identifying the various factors that influence student preferences and positive learning outcomes and in discovering that all formats can be effective in some circumstances.

The concept of "chunking" information, i.e. dividing the instruction into smaller, more manageable pieces, is mentioned by Mestre $(2010,2012)$ as an effective way to address learning styles and reduce cognitive load. Similar concepts such as learning objects or modules are mentioned by others as ways to make tutorials flexible and relevant (Halpern \& Tucker, 2015). The modular organization allows librarians and faculty to direct students to only those modules that are relevant for an assignment or a course. Chunking information and using learning modules allows students to self-determine their point of entry into a learning task and repeat learning tasks as needed.

One recommendation made repeatedly in the literature is for tutorials to be presented to students at a "point of need" or "just in time" (Artemchik, 2016; Bowles-Terry et al., 2010; Halpern \& Tucker, 2015; Held \& Gil-Trejo, 2016; Hess \& Hristova, 2016; Mestre, 2010; Turner 
et al., 2015). This practice has two parts: first, the tutorials should be problem- or task-based.

Second, the tutorials should be linked throughout the library's web site at points where students may benefit from additional instruction. If instruction is based on a task or a problem that a student must accomplish, students can understand the value of it and be motivated to learn (Stiwinter, 2013).

Many studies concluded that one type of tutorial proved to be best for most students. Reasoning that librarians wish to instruct all students and not just most, librarians should present different types of tutorials so that students with different learning styles can choose which would be most appropriate (Bowles-Terry et al., 2010; Gonzales, 2014; Mestre, 2010; Mestre, 2012; Mikkelson \& McMunn-Tetangco, 2014). In her study of student preferences for tutorial design, Mestre (2012) concluded that information need is also a factor that influences students' preferences. Multiple tutorial techniques should be provided not only to accommodate different learning styles, but also for students to self-determine what technique is best for them for any given information need.

\section{Learning styles and andragogy}

Several studies mentioned the influence of individual learning styles on learning outcomes and student preference for tutorial types (Bowles-Terry, et al., 2010; Gonzales, 2014; Held \& Gil-Trejo, 2016; Mikkelsen \& McMunn-Tetangco, 2014). However, the studies that directly addressed the relationship between learning styles and effective tutorials found no direct relationship between the two. Students with different learning styles learned better with static web pages over video screencasts (Mestre, 2010; Mestre, 2012). Of greater importance to students were the above-mentioned ability to control the pace, choose parts to review, and actively follow the steps of the tutorial. Throughout the literature, preferences such as these are 
indicative of qualities of adult learners. Although Malcolm Knowles' principles of andragogy are mentioned explicitly only by some (Dewald, 1999; Halpern \& Tucker, 2015; Lange et al., 2011), students' self-reporting of these characteristics described by Knowles indicate that his principles can support effective design of online instruction.

In 1950, Knowles began studying and writing about how adults learned - termed "andragogy" as distinct from children's learning or pedagogy. He did not mark a definitive age as to when a person learns like an adult: rather he observed that as individuals grow from childhood to adulthood, their needs as learners change and develop (Knowles, Holton, \& Swanson, 2015). In the field of education, adult learners, also called non-traditional students, are generally defined as being over age twenty-four and having significant family and work responsibilities in addition to attending school (National Center for Education Statistics, 1996). But Knowles et al. (2015) made the observation that most individuals develop adult learning characteristics well before age twenty-four. They note that the need to learn as adults "increases rapidly during adolescence" (p. 62) and that most, if not all, individuals demonstrate adult learner characteristics by age nineteen.

One important development observed by Knowles et al. (2015) is adult learners' selfperception as independent learners, as opposed to children who are dependent learners. Some ways this appears in practice are as a desire to self-pace learning, to be able to integrate prior learning into instruction, and to be able to see a practical application for the instruction. All of these characteristics appear in the literature as important best practices for library tutorials. Selfpaced tutorials, self-directed learning, problem-based instruction, point-of-need instruction, and chunking information into learning modules were noted as optimal both for student preference and for effective learning. Both the student preference for and the optimal learning outcomes of 
these techniques indicate that the learners studied perceive themselves as independent learners who prefer to be self-directed, have some degree of control over the learning environment, and need to know why the instruction is important.

Two studies in the examined literature that specifically evaluated the practical application of andragogy to online library tutorials focused on adult learners as key users of asynchronous library instruction. Lange et al. (2011) discussed how they adapted library instruction for continuing education students whose average age was thirty-three. Halpern and Tucker (2015), offering a conceptual examination of the application of adult learning principles to online library tutorials, noted its necessity due to the large number of nontraditional students at many colleges and universities. Of note, however, is that with the exceptions mentioned above, the studies in the literature mentioned here did not distinguish students by age. The students who reported preferences for adult learning styles were simply undergraduates in a variety of contexts: large public universities, private liberal arts universities, and a community college. Students in some studies were recruited via student newspapers, others via on-campus flyers, and others in individual undergraduate courses. Given the context of the studies, many students were likely traditional age college students. Sachs, Langan, Leatherman, and Walter's (2013) study of millennial college students found that students learned equally well using static web page tutorials and a "Millennial-friendly" tutorial - one that included more visuals and less text, was concise, had opportunities to practice the skill, and gave feedback - but they preferred the latter. This study, and the others examined here, raise the question: do undergraduates prefer these types of tutorials because they are Millennials or traditional age or non-traditional college students or because most undergraduates, regardless of age, learn like adults?

\section{Conclusion}


If there is one consensus to draw from the examined literature, it is that college students, regardless of whether they are traditional or non-traditional college students, display the characteristics of adult learners. They like to know their learning is relevant. They learn best when tutorials are problem-based. They come to library instruction with prior learning that needs to be accommodated. They prefer, and are capable of, self-directing their learning. These characteristics - those of andragogy - were addressed as essential best practices, even if they were not named specifically as adult learning characteristics. Effective online instruction occurs when college students' adult learning characteristics are strategically applied to design and delivery.

Regarding specific instructional delivery methods and techniques, no general conclusions can be drawn. The studies determined that interactive tutorials are effective, but are not always best for all students with all information needs. Web simulation in video screencasts is a helpful technique, but static web pages are also an effective instructional method and better account for students' prior knowledge and are easier for students to refer back to. Students' preferences for online instruction methods may be influenced more by their learning needs than their learning styles. The perhaps not so helpful conclusion is that most methods work well at least some of the time and for some students. The more helpful conclusion drawn from the literature, mentioned above, is that librarians should use the principles of andragogy to design online instruction, whatever method or format is used. 


\section{References}

Artemchik, T. (2016). Using the instructional design process in tutorial development. Reference Services Review, 44, 309-323. doi:10.1108/RSR-12-2015-0050.

Bowles-Terry, M., Hensley, M. K., \& Hinchliffe, L. J. (2010). Best practices for online video tutorials in academic libraries: A study of student preferences and understanding. Communications in Information Literacy 4(1), 17-28.

Dewald, N. H. (1999). Web-based library instruction: What is good pedagogy? Information Technology and Libraries 18(1), 26-31.

Gonzales, B. M. (2014). Online tutorials and effective information literacy instruction for distance learners. Journal of Library \& Information Services in Distance Learning, 8, 4555. doi:10.1080/1533290X.2014.898011.

Halpern, R., \& Tucker, C. (2015). Leveraging adult learning theory with online tutorials. Reference Services Review, 43(1), 112-124. doi:10.1108/RSR-10-2014-0042.

Held, T., \& Gil-Trejo, L. (2016). Students weigh in: Usability test of online library tutorials. Internet Reference Services Quarterly, 21(1/2), 1-21. doi:10.1080/10875301.2016.1164786.

Hess, A. N., \& Hristova, M. (2016). To search or to browse: How users navigate a new interface for online library tutorials, College \& Undergraduate Libraries, 23(2), 168-183. doi:10.1080/10691316.2014.963274.

Knowles, M. S., Holton, E. F., \& Swanson, R. A. (2015). The adult learner: The definitive classic in adult education and human resource development. New York, NY: Routledge. 
Lange, J., Canuel, R. \& Fitzgibbons, M. (2011). Tailoring information literacy instruction and library services for continuing education. Journal of Information Literacy 5(2), 66-80. doi:10.11645/5.2.1606.

Mery, Y., DeFrain, E., Kline, E., \& Sult, L. (2014). Evaluating the effectiveness of tools for online database instruction. Communications in Information Literacy, 8(1), 70-81.

Mestre, L. S. (2010). Matching up learning styles with learning objects: What's effective? Journal of Library Administration, 50(7/8), 808-829. doi:10.1080/01930826.2010.488975.

Mestre, L. S. (2012). Student preference for tutorial design: A usability study. Reference Services Review, 40(2), 258-276. doi:10.1108/00907321211228318.

Mikkelsen, S. \& McMunn-Tetangco, E. (2014) Guide on the Side: Testing the tool and the tutorials. Internet Reference Services Quarterly, 19(3-4), 271-282. doi:10.1080/10875301.2014.948252.

Sachs, D. E., Langan, K. A., Leatherman, C. C., \& Walters, J. L. (2013) Assessing the effectiveness of online instruction literacy tutorials for millennial undergraduates. College \& Undergraduate Libraries, 20(3-4), 327-351. doi:10.1080/10691316.2013.829365.

Scales, B. J., Nicol, E., \& Johnson, C. M. (2014). Redesigning comprehensive library tutorials: Theoretical considerations for multimedia enhancements and student learning. Reference \& User Services Quarterly, 53(3), 242-52.

Stiwinter, K. (2013). Using an interactive online tutorial to expand library instruction. Internet Reference Services Quarterly, 18(1), 15-41. doi:10.1080/10875301.2013.777010. 
Stonebraker, I., Robertshaw, M. B., \& Moss, J. D. (2016). Student see versus student do: A comparative study of two online tutorials. TechTrends, 60, 176-182. doi:10.1007/s11528016-0026-7.

Turner, B., Fuchs, C., \& Todman, A. (2015). Static vs. dynamic tutorials: Applying usability principles to evaluate online point-of-need instruction. Information Technology \& Libraries, 34(4), 30-54. doi:10.6017/ital.v34i4.5831

United States Department of Education. National Center for Education Statistics. (1996). Nontraditional undergraduates: Trends in enrollment from 1986 to 1992 and persistence and attainment among 1989-90 beginning postsecondary students. Retrieved from https://nces.ed.gov/pubs/web/97578e.asp 